\title{
A comunidade de abelhas (Hymenoptera, Apidae s. I.) em uma área restrita de campo natural no Parque Estadual de Vila Velha, Paraná: diversidade, fenologia e fontes florais de alimento $^{1}$
}

\author{
Rodrigo B. Gonçalves ${ }^{2,3}$ \& Gabriel A. R. $\mathrm{Melo}^{2,4}$
}

\author{
${ }^{1}$ Contribuição $\mathrm{n}^{\circ} .1558$ do Departamento de Zoologia da Universidade Federal do Paraná. \\ ${ }^{2}$ Laboratório de Biologia Comparada de Hymenoptera, Departamento de Zoologia, Universidade Federal do Paraná, Caixa Postal 19020, \\ 81531-980 Curitiba-PR, Brasil. \\ ${ }^{3}$ Programa de Pós-Graduação em Entomologia (UFPR). goncalvesrb@yahoo.com.br \\ ${ }^{4}$ Bolsista PQ 2 (CNPq). garmelo@ufpr.br
}

\begin{abstract}
The bee community (Hymenoptera, Apidae s. 1.) in a restricted area of native grassland in the Vila Velha State Park, Paraná: diversity, phenology and food plants. A standardized survey of bees visiting blooming plants in an area covered by natural grasslands in the Vila Velha State Park was conducted from October, 2002, to October, 2003. A total of 1552 specimens belonging to 181 species were collected. These species are distributed in 58 genera, 24 tribes and 5 subfamilies. The visited plants belong to 113 species, in 72 genera and 38 families. Megachile, with 20 species, was the richest genus, while Ceratina was the most abundant native genus. Apis mellifera was the most abundant species, with $28 \%$ of all bees collected. Among the native species, Bombus atratus was the most abundant. Monthly richness and equitability varied along the year, March being the richest, and November, the most equitable. Despite being traditionally placed within the southern steppes, the open grasslands of Vila Velha contain numerous species previously only known from the cerrados of central Brazil. Also, when compared to other areas with open vegetation in Brazil, the bee fauna of Vila Velha stands out for having the subfamilies Apinae and Halictinae with equal number of species. Lists of bee species and of their host plants are appended.
\end{abstract}

KEYWORDS. Apoidea; natural grasslands; Neotropical; savanna; survey.

\begin{abstract}
RESUMO. A comunidade de abelhas (Hymenoptera, Apidae s. 1.) em uma área restrita de campo natural no Parque Estadual de Vila Velha, Paraná: diversidade, fenologia e fontes florais de alimento. Coletas sistemáticas de abelhas em uma área restrita no Parque Estadual de Vila Velha, Paraná, no período de outubro de 2002 a outubro de 2003, resultaram em 1552 espécimes pertencentes a 181 espécies. Estas espécies estão distribuídas em 58 gêneros, 24 tribos e 5 subfamílias. As plantas visitadas correspondem a 113 espécies, em 72 gêneros e 38 famílias. Megachile com 20 espécies foi o gênero mais rico e Ceratina o gênero mais abundante dentre os gêneros nativos. Apis mellifera foi a espécie mais coletada, correspondendo a $28 \%$ do total de indivíduos, e Bombus atratus foi a espécie mais abundante dentre as abelhas nativas. A riqueza e a equitabilidade nos meses foram variáveis, sendo março o mais rico e novembro o de maior equitabilidade. Apesar de tradicionalmente considerados parte das estepes sulinas, os campos de Vila Velha apresentam uma fauna de abelhas contendo várias espécies típicas de cerrado. O igual número de espécies entre as subfamílias Apinae e Halictinae também apontam para uma peculiaridade de sua fauna. Listas de abelhas e plantas coletadas são apresentadas em anexo.
\end{abstract}

PALAVRAS-CHAVE. Apoidea; campos gerais; levantamento; Neotropical; savana.

Para expandir o conhecimento sobre nossa fauna de abelhas são necessários estudos sobre a sua composição e a distribuição de suas espécies (Silveira \& Godínez 1996). Visto que é preocupante o grau de degradação em que se encontram as áreas naturais no estado do Paraná e no Brasil, o monitoramento de alterações antrópicas de ambientes (Bortoli \& Laroca 1990, Taura \& Laroca 2001) é também altamente valioso. Para isso, no entanto, é necessário que levantamentos em áreas melhor preservadas sejam conduzidos, a fim de fornecer subsídios para as ações de monitoramento.

Os principais propósitos dos primeiros levantamentos de abelhas foram a obtenção de informações sobre a sazonalidade das espécies e a estrutura específica da comunidade de abelhas (a partir de Sakagami et al. 1967). Hoje os levantamentos, sobretudo aqueles conduzidos em áreas restritas, são realizados também no intuito de entender a distribuição geográfica das abelhas e de comparar diferentes áreas a partir da sua riqueza e diversidade.

O estado do Paraná abrigou um grande número de levantamentos de faunas de abelhas, em torno de 16, mas esses estudos estiveram concentrados no litoral, primeiro e terceiro planaltos, com apenas dois estudos prévios realizados no segundo planalto (Barbola \& Laroca 1993; Almeida 2003). Já as áreas de campos naturais só foram investigadas em três estudos (Sakagami et al. 1967, Barbola \& Laroca 1993, Bortoli $\&$ Laroca 1997). No estado do Rio Grande do Sul somente o estudo de Hoffmann (1990), em Viamão, amostrou uma fauna de campos semelhantes aos campos paranaenses. Portanto regiões naturais cobertas por esse tipo de vegetação carecem de estudos sobre a fauna de abelhas.

Esse trabalho pretende fornecer dados sobre a comunidade de abelhas em uma área restrita de campos naturais pertencente 
ao segundo planalto paranaense. A composição de espécies e suas abundâncias, bem como suas relações com fontes alimentares são apresentadas e discutidas.

\section{MATERIAL E MÉTODOS}

\section{Área de estudo}

O Parque Estadual de Vila Velha (PEVV) está localizado entre as coordenadas $25^{\circ} 12^{\prime} 34^{\prime \prime}$ e $25^{\circ} 15^{\prime} 35^{\prime \prime}$ de latitude Sul e 49 58' 04" e 5003'37" de longitude Oeste, no município de Ponta Grossa. Possui uma área de 3.122,11 hectares e é conhecido por seus arenitos, que devido à sua expressiva beleza cênica constituem o principal atrativo turístico do Parque. Dentre as estepes paranaenses somente aquelas porções presentes no Parque estão resguardadas como Unidade de Conservação de uso indireto.

O clima segundo a classificação de Köppen é do tipo $\mathrm{Cfb}$, com temperatura média no mês mais frio abaixo de $18^{\circ} \mathrm{C}$, com verões frescos, temperatura média no mês mais quente de $22^{\circ} \mathrm{C}$ e sem estação seca definida.

Segundo Ziller (2000), a cobertura vegetacional dominante no PEVV é de estepe gramíneo-lenhosa (classificação do IBGE) conhecida como campos gerais, campos sulinos ou campos naturais. O domínio fitofisionômico dessas estepes é de gramíneas, ciperáceas, asteráceas, verbenáceas e leguminosas (Klein \& Hatschbach 1971). Associados à estepe são encontradas: floresta ombrófila mista (mata de araucária) representada por pequenos capões freqüentemente associados a solos úmidos e borda de rios; espécies de plantas típicas de cerrado, porém sem caracterizar áreas com fisionomia desse bioma; e por fim, refúgios vegetacionais rupestres (Ziller 2000).

A área de coleta possui cerca de seis hectares e está inserida nos arredores da localidade denominada Fortaleza, entre as coordenadas $25^{\circ} 13^{\prime} 47,9^{\prime \prime}$ e $25^{\circ} 13^{\prime} 55,8^{\prime \prime}$ de latitude $\mathrm{S} \mathrm{e}$ 4959’26,9" e 4959’42,6" de longitude W. Nessa área é encontrada uma combinação de paisagens que inclui campo sujo com predominância de asteráceas, borda de mata de araucária, vegetação rupícola associada com os arenitos e por fim um aceiro, isto é, uma faixa com cerca de $10 \mathrm{~m}$ de largura cuja vegetação é cortada periodicamente por máquinas (Fig. 1).

\section{Amostragem, identificação e análise dos dados}

A amostragem foi efetuada por meio de coletas mensais, cada uma realizada em um único dia e com oito horas de duração. As coletas foram realizadas entre os meses de outubro de 2002 e outubro de 2003, perfazendo um total de 10 coletas. Dadas as baixas temperaturas médias históricas para os meses de junho a agosto e a conseqüente redução na atividade dos insetos e na presença de plantas floridas, estes meses não foram amostrados em 2003 . Uma $11^{\text {a }}$ coleta, realizada no dia 07 de dezembro de 2002, foi descartada por ter sido interrompida prematuramente por uma chuva prolongada (elevadas precipitações em outras datas não afetaram a amostragem por não terem coincidido com os horários de coleta).
O horário aproximado de início foi às oito horas da manhã e o de término às 16 horas. Dois coletores munidos de redes entomológicas e de frascos mortíferos percorriam aleatoriamente a área para captura das abelhas. As plantas que estavam floridas eram observadas por em média trinta segundos, ou no máximo por dois minutos caso houvesse o forrageio intenso de abelhas. As abelhas que forrageavam suor nos coletores ou aquelas que se encontravam em vôo foram também capturadas. Os indivíduos capturados foram separados em envelopes de papel de acordo com a planta e horário de coleta. As abelhas da espécie Apis mellifera foram quantificadas em campo através de captura ou de contagem visual. As plantas visitadas foram fotografadas com câmera digital para montagem de acervo fotográfico e amostradas para herborização.

Após a separação em morfo-espécies, as abelhas foram identificadas por meio de chaves específicas, por comparações com exemplares depositados na coleção de Entomologia da UFPR e por especialistas. As plantas foram enviadas para identificação no Herbário da Universidade Federal do Paraná, e para o Herbário Municipal de Curitiba. As abelhas foram depositadas na Coleção Padre Jesus S. Moure (DZUP) e as plantas no Herbário da Universidade Federal do Paraná (UPCB).

Os dados metereológicos referentes à temperatura média diária, velocidade do vento e precipitação acumulada foram obtidos junto ao Instituto Tecnológico SIMEPAR, referentes à estação de Ponta Grossa, localizada a aproximadamente 15 km do Parque, nas coordenadas de $25^{\circ} 12^{\prime} 59^{\prime \prime} \mathrm{S}$ e $50^{\circ} 00^{\prime} 59^{\prime \prime} \mathrm{W}$.

Além da análise qualitativa, são apresentadas duas análises quantitativas para a comparação entre as coletas mensais. Foi calculado para cada coleta o número esperado de espécies para diferentes tamanhos amostrais, método de rarefação (Sanders 1968; Hulbert 1971; Simberloff 1972). Os números calculados para 32, 50 e 80 indivíduos não computam a abelha A. mellifera. A riqueza esperada para 50 e 80 indivíduos não foi calculada para os meses de maio (em ambos) e de novembro (no segundo apenas) devido às baixas abundâncias nesses meses.

Também foi calculada a probabilidade de encontro interespecifico (PEI, Hulbert 1971) que se trata da probabilidade de dois indivíduos retirados ao acaso pertençam a duas espécies diferentes. Os dois cálculos acima mencionados foram realizados no programa EcoSim (Gotelli \& Entsminger 2005).

A classificação das abelhas aqui adotada admite apenas uma família (Melo \& Gonçalves 2005), sendo que as famílias reconhecidas na classificação tradicional (p. ex. Silveira et al. 2002) são tratadas como subfamílias. Porém, a maioria das tribos possui o mesmo escopo entre as classificações.

\section{RESULTADOS}

\section{Riqueza e abundância das abelhas}

Foram coletados 1552 espécimes de abelhas correspondendo a 181 morfo-espécies, das quais 103 puderam ser identificadas até espécie. As espécies encontradas estão 

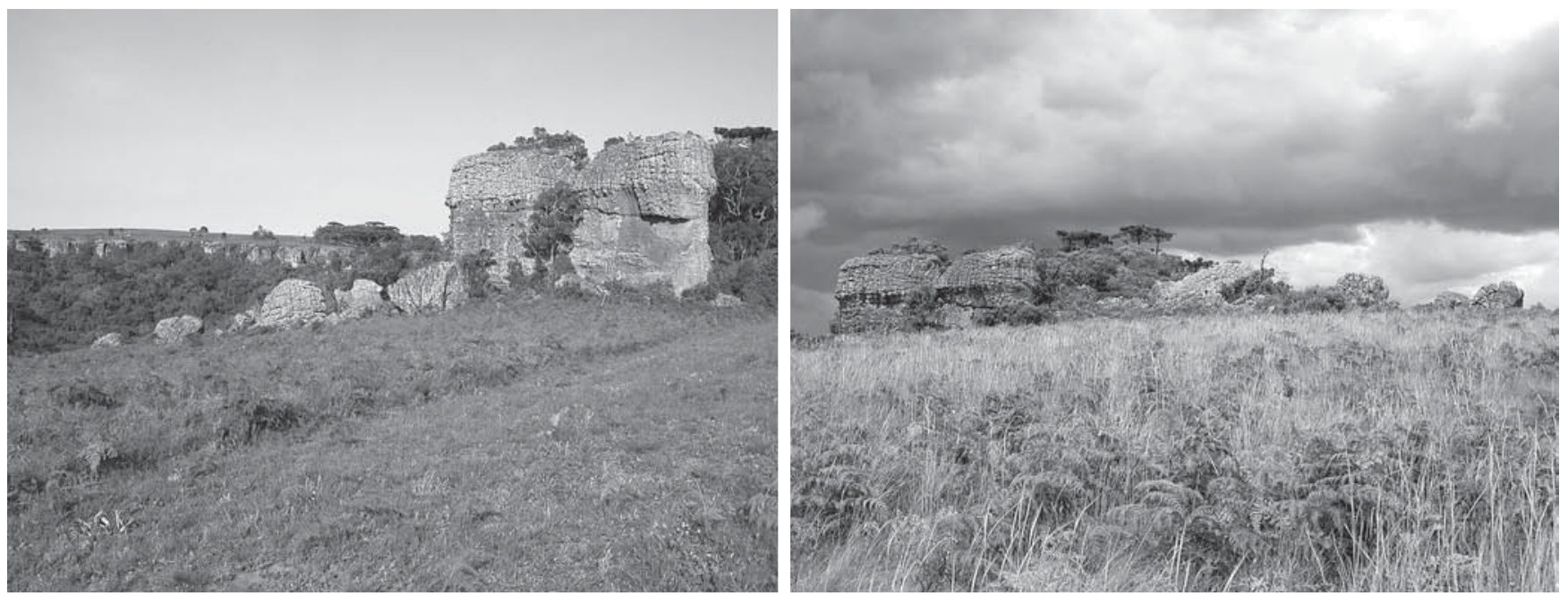

Fig. 1. Vistas parciais da área de estudo no Parque Estadual de Vila Velha. Em ambas, os blocos maiores de arenito são os mesmos. À esquerda, pode ser visto, em primeiro plano, o aceiro que corta a área.

distribuídas em 59 gêneros, 23 tribos e 5 subfamílias. Do total de indivíduos, 178 são machos, na proporção aproximada de 7,7 fêmeas por macho, ou 5,5 quando se excluem as operárias de Apis mellifera. Foram coletados em média 20 indivíduos por hora, 8,5 indivíduos por espécie e 42 espécies de abelhas por coleta. A lista das espécies consta no Apêndice I.

A ordem de riqueza para Vila Velha foi Halictinae $=$ Apinae $>$ Megachilinae $>$ Andreninae $>$ Colletinae (Tabela I). Quando se dissocia Apini (abelhas corbiculadas) de Apinae, representando a antiga dicotomia entre "Apidae" e "Anthophoridae", a ordem encontrada é Halictinae > Apinae menos Apini $>$ Megachilinae $>$ Andreninae $>$ Colletinae $>$ Apini. A ordem decrescente de abundância encontrada é Apinae $>$ Halictinae $>$ Andreninae $>$ Megachilinae $>$ Colletinae, incluídos ou não os indivíduos de $A$. mellifera. A maior abundância de Apinae deve-se, em parte, às espécies sociais, especialmente A. mellifera, Bombus atratus e Scaptorigona bipunctata, e ao gênero Ceratina que apresentou pelo menos três espécies muito abundantes (Apêndice I). Descontando os indivíduos de Apini (664 no total), a subfamília Apinae é a segunda mais abundante ficando atrás de Halictinae.

Andreninae e Megachilinae apresentam uma relação inversa entre riqueza e abundância. A maior riqueza de Megachilinae está concentrada em Megachile, o gênero mais rico do levantamento (20 espécies), porém essa subfamília apresenta um baixo número de indivíduos por espécie $(2,5)$. Em Andreninae, Rhophitulus apresenta um alto número de indivíduos (92), sendo o responsável pela elevada abundância da subfamília.

Com exceção de Megachile, os demais gêneros que apresentaram elevada riqueza também exibiram elevada abundância. Portanto, os demais gêneros de maior riqueza foram os também abundantes halictíneos Dialictus (17 espécies, em geral o mais rico nos levantamentos paranaenses) e Augochloropsis (15), o apíneo Ceratina (12) e o andreníneo Rhophitulus (8).
Bombus atratus seguido de Scaptotrigona bipunctata, Ceratina (Crewella) sp.2, Dialictus sp.4, e Rhophitulus aff. steinbachi foram as abelhas nativas mais abundantes (Apêndice I). Os gêneros nativos mais abundantes foram, em seqüência decrescente: Ceratina, Bombus, Augochloropsis, Dialictus e Rhophitulus.

\section{Perfil das coletas e das variações sazonais}

As Figuras 2 e 3 apresentam, respectivamente, a riqueza observada e esperada para diferentes amostras e o PEI para cada coleta. Meses com alta equitabilidade (Fig. 3) mostram uma riqueza esperada em pequenas amostras (Fig. 2) relativamente próxima da riqueza amostrada.

As abelhas predominantes em outubro de 2002 e outubro de 2003 foram distintas: Scaptotrigona, Ceratina e Hylaeus (este último gênero com quatro espécies forrageando em Litrhaea aroeirinha, Anacardiaceae) foram abundantes em 2002, enquanto Augochloropsis e Dialictus o foram em 2003. Em ambos os meses, o cacto Parodia ottonis esteve florido.

Novembro apresentou a maior proporção de encontro interespecífico (PEI), o que coincide com o baixo número de indivíduos por espécie $(1,7)$, representando uma notável equitabilidade para esse mês. As plantas mais visitadas neste mês foram: Peltodon rugosus (Lamiaceae), Senecio brasiliensis (Asteraceae), Wahlenbergia linarioides (Campanulaceae) e Ipomoea spp (Convolvulaceae).

Durante os meses mais quentes, de dezembro a março, 133 espécies de abelhas foram coletadas. As florações em massa também foram características desses meses, especialmente a asterácea Verbesina sordescens que esteve florida com intensidade, especialmente em fevereiro. Características específicas de cada mês foram a presença de 12 espécies de Dialictus e a floração das palmeiras (Arecaceae) em dezembro; a floração das Fabaceae em janeiro; as espécies de Vernonia (Asteraceae) em fevereiro e a alta riqueza relativa de março. A coleta deste mês apresentou o maior número de indivíduos e 
Tabela I. Número de espécies e indivíduos por subfamília.

\begin{tabular}{lcc}
\hline Subfamília & $\mathrm{N}^{\circ}$. espécies & $\mathrm{N}^{\circ}$. indivíduos \\
\hline Andreninae & 19 & 115 \\
Apinae & 58 & $945\left(511^{*}\right)$ \\
Colletinae & 17 & 42 \\
Halictinae & 58 & 376 \\
Megachilinae & 29 & 74 \\
Total & 181 & 1552 \\
\hline
\end{tabular}

* Total de indivíduos excluindo Apis mellifera.

de espécies coletados do que em outras coletas, $35 \%$ do total de espécies foram coletadas e destas 20 espécies foram únicas a esse mês.

É importante chamar atenção para o número elevado de espécies que só foram coletadas na amostragem do dia 07 de dezembro de 2002, que foi substituída por uma realizada no dia 12 do referido mês (vide Material e Métodos). Entre essas espécies estão quatro da tribo Tapinotaspidini (Arhysoceble $s p$, Caenonomada labrata Zanella, Paratetrapedia volatilis (Smith) e Trigonopedia sp), além de um Emphorini (Melitoma $s p$ ) e um Halictini (Pseudagapostemon tesselatus Cure). A inclusão destas espécies elevaria a riqueza de Vila Velha para 189 espécies, e a inclusão dos indivíduos coletados nessa data aumentaria a abundância para 1671 espécimes.

As coletas de abril e maio apresentaram acentuada diminuição do número de indivíduos e espécies coletadas, especialmente no último mês quando somente 16 espécies foram coletadas. Nesse mês houve o predomínio de abelhas com tamanho corporal pequeno, como os gêneros Ceratina (cinco espécies coletadas), Ceratalictus, Chilicola e Hylaeus. Abelhas grandes, como Bombus, Centris e Xylocopa, não foram encontradas em atividade, embora a presença de Bombus fosse esperada.

No mês de setembro, as plantas Maytenus robusta (Celastraceae) e Symplocos pentandra (Symplocaceae),

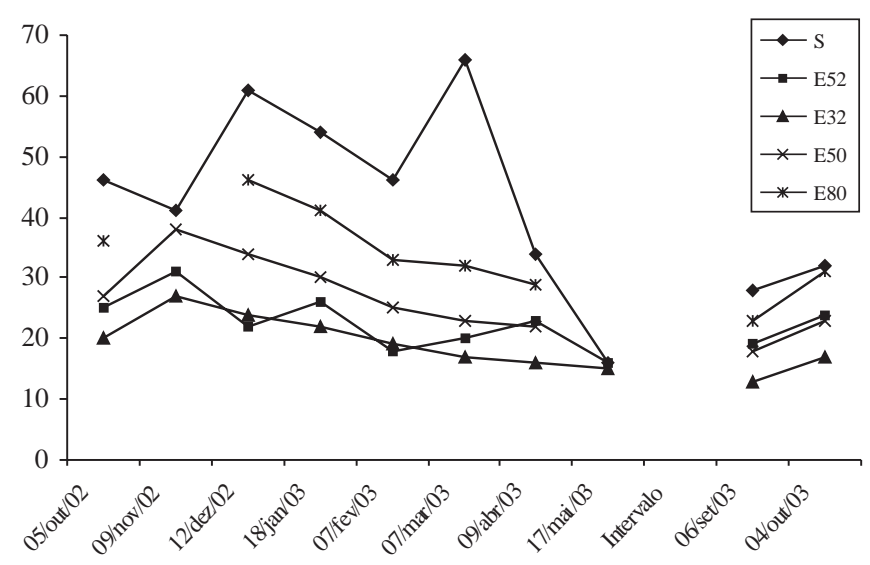

Fig. 2. Número observado (S) e esperado de espécies para 52 indivíduos (E52) incluindo Apis mellifera, 32 indivíduos (E32) excluindo A. mellifera, 50 indivíduos (E50) exceto o mês de maio e 80 indivíduos (E80) exceto os meses de maio e novembro. O intervalo corresponde aos meses de junho a agosto de 2003. espécies associadas à floresta ombrófila mista (Ziller 2000) receberam visitas de Ceratina (em ambas espécies de plantas), Chilicola (apenas em Maytenus) e Caenohalictus (apenas em Maytenus). Asteraceae não foi representativa como nos meses anteriores; além de Maytenus e Symplocos, outras plantas, como Rhynchospora setigera (Cyperaceae, abundante também no mês seguinte) e Eriocaulum dictyophyllum (Eriocaulaceae), foram intensamente visitadas nesse mês.

\section{Plantas visitadas}

Dentre as 1552 abelhas coletadas em Vila Velha, 1388 (89\%) foram capturadas em visita a flores, sendo estas pertencentes a 113 espécies, 77 gêneros e 38 famílias. A lista das plantas visitadas encontra-se no Apêndice II.

Asteraceae é a família mais rica (43 espécies), aquela que recebeu a maioria das visitas de abelhas $(55 \%)$ e por fim a que hospedou o maior número de espécies de abelhas (80 espécies). Nessa família, destacam-se os gêneros Verbesina (com 194 abelhas coletadas), Vernonia (134), Baccharis (118) e Eupatorium (85). Por fim, na maioria dos meses do ano, Asteraceae foi a família mais visitada.

Apiaceae recebeu visitas de 36 espécies de abelhas (159 indivíduos), todas associadas às espécies do gênero Eryngium. Esse gênero foi o mais visitado por abelhas nativas, e teve poucas visitas de Apis. Fabaceae foi a terceira família com o maior número de espécies de abelhas associadas (35) e em número de indivíduos associados (70). Os gêneros Centrosema e Crotalaria merecem destaque quanto à visitação (Tabela III).

As três famílias de plantas citadas anteriormente receberam juntas a visita de 105 espécies de abelhas correspondendo a $59 \%$ das espécies coletadas no presente trabalho. As demais espécies de abelhas foram encontradas forrageando em outras 36 famílias. Mais sete famílias se mostraram importantes (Tabela III); nelas merecem destaque os gêneros Borreria (Rubiaceae) e Chamaecrista (Caesalpinaceae) e as espécies Parodia ottonis (Cactaceae), Litrhaea aroeirinha (Anacardiaceae) e Peltodon rugosus (Lamiaceae).

Quando se excluem os dados referentes a Apis mellifera (Tabela III), nota-se mudança no ordenamento dos gêneros mais visitados (vide Verbesina $\mathrm{x}$ Apiaceae), devido à clara preferência de Apis por asteráceas que apresentam florações em massa. Por exemplo, todas as 20 visitas ao gênero Symphyopappus (Asteraceae), que apresentou uma florada maciça em fevereiro de 2003, foram dessa abelha.

Apesar de não ter sido o foco do trabalho, foi possível detectar vários casos de especialização entre as espécies coletadas, como por exemplo, as abelhas do gênero Rhophitulus (Protandrenini) capturadas em apenas uma espécie de planta: Rhophitulus aff. holosticus visitou somente Caesarea albiflora; $R$. aff. steinbachi $\mathrm{e}$ R. sp.5 visitaram apenas Eryngium junceum (Apiaceae); e $R$. anomalus só foi encontrado em Sida macrodon (Malvaceae). A abelha Callonychium petuniae (Protandrenini) descrita como especialista em Petunia (Wittmann et al. 1990) visitou quase 
Tabela II. Data das coletas; número total de horas de coleta por coletor, abundância, porcentagem de indivíduos de Apis mellifera, número de espécies, probabilidade de encontro interespecífico (PEI), temperatura média (TM, em $\left.{ }^{\circ} \mathrm{C}\right)$, velocidade do vento média (VV, em m/s) e precipitação acumulada (PA, em $\mathrm{mm}$ ).

\begin{tabular}{|c|c|c|c|c|c|c|c|c|}
\hline Data & Horas & $\mathrm{N}^{\circ}$. ind. & $\%$ Apis & $\mathrm{N}^{\circ}$. sp. & PEI & $\mathrm{TM}$ & VV & PA \\
\hline $5 / \mathrm{X} / 2002$ & $07: 19$ & 156 & $19,23 \%$ & 46 & 0,93079 & 21 & 2,6 & 0 \\
\hline 9/XI/2002 & $08: 52$ & 72 & $29,17 \%$ & 41 & 0,98667 & 20,5 & 4,8 & 0 \\
\hline 12/XII/2002 & $08: 10$ & 229 & $48,03 \%$ & 61 & 0,97678 & 21,1 & 1,8 & 0 \\
\hline 18/I/2003 & 09:13 & 165 & $24,85 \%$ & 54 & 0,95188 & 22,6 & 2,2 & 0 \\
\hline 7/II/2003 & 08:20 & 242 & $45,87 \%$ & 46 & 0,9488 & 22,8 & 2,1 & 7,4 \\
\hline 7/III/2003 & $07: 20$ & 332 & $27,49 \%$ & 66 & 0,9008 & 22 & 1,9 & 14,8 \\
\hline 9/IV/2003 & $07: 36$ & 101 & $2,88 \%$ & 34 & 0,89838 & 19,4 & 2,9 & 6,6 \\
\hline $17 / \mathrm{V} / 2003$ & $06: 56$ & 52 & $37,74 \%$ & 16 & 0,85282 & 18,7 & 2,1 & 0 \\
\hline 6/IX/2003 & $06: 18$ & 116 & $5,26 \%$ & 28 & 0,88257 & 20,3 & 3,5 & 0 \\
\hline $4 / \mathrm{X} / 2003$ & 07:08 & 88 & $1,14 \%$ & 32 & 0,92355 & 21 & 4,8 & 0 \\
\hline Total & $77: 12$ & 1553 & $28 \%$ & & & & & \\
\hline
\end{tabular}

exclusivamente flores de Callibrachoa spp (anteriormente reconhecida como subgênero de Petunia).

Outro tipo de especialização é o caso das abelhas coletoras de óleos florais. Várias espécies de plantas oferecem óleo como recompensa para seus polinizadores. Na Tabela IV estão registradas as visitas de abelhas que coletam óleo e as respectivas espécies botânicas relacionadas.

Três espécies de plantas visitadas pelas abelhas merecem destaque por serem raras e/ou ameaçadas de extinção. A Amaranthaceae Gomphrena macrocephala, indicada como em risco de extinção (Takeda \& Faraco 2001), foi visitada nos meses de dezembro e fevereiro por Ceratina (Crewella) sp.2. Outra espécie ameaçada, Parodia ottonis, floriu em setembro e outubro e recebeu muitas visitas de Ceratina (Rhysoceratina) sp.1 e Dialictus sp.4, e visitas eventuais dos gêneros Ancyloscelis, Augochloropsis, Callonynchium, Megachile e Psaenythia. Por fim, o maracujá Passiflora lepidota que possui apenas três registros anteriores para o Paraná, foi visitado em dezembro por Bombus morio.

\section{DISCUSSÃO}

\section{Riqueza e abundância das abelhas}

A riqueza e a abundância de abelhas de Vila Velha são

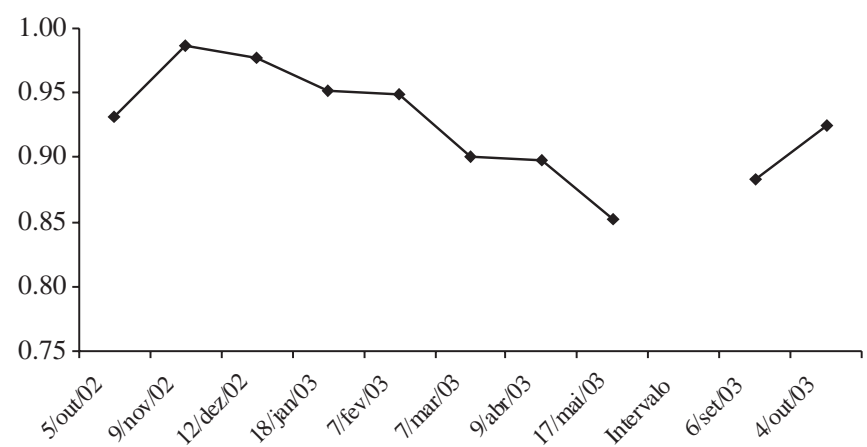

Fig. 3. Proporção de encontro interespecifico (PEI) para cada data de coleta. A interrupção (intervalo) corresponde aos meses de junho a agosto de 2003 quando não foram realizadas coletas. comparáveis às obtidas em outros estudos realizados no estado (Bortoli \& Laroca 1997, Sakagami et al. 1967) e no país (p.ex. Alves-dos-Santos 1999, Silveira \& Campos 1995). O padrão geral de ordem de riqueza encontrado nos levantamentos realizados no Paraná revela Halictinae como sendo mais rica que Apinae. Porém essa diferença varia muito conforme a área; em São José dos Pinhais, o número de espécies de Apinae corresponde a 37,5\% do número de espécies de Halictinae, ao passo que em Lapa, essa relação é de $76,6 \%$ e em Guarapuava, de $98 \%$. Em estudos conduzidos em áreas com vegetação aberta no Rio Grande do Sul (Hoffmann 1990; Schlindwein 1995) e no cerrado (Silveira \& Campos 1995), incluindo o paranaense (Almeida 2003), Apinae é o grupo mais rico, com até o triplo de espécies de Halictinae.

A fauna de Vila Velha apresenta uma posição intermediária, pois a igualdade de riqueza entre essas subfamílias não é observada em nenhum outro estudo. Tanto o maior número de espécies de Apinae e o menor número de espécies de Halictinae, em relação aos números encontrados nos campos naturais do estado, contribuem para essa igualdade.

A abelha introduzida Apis mellifera correspondeu a $28 \%$ das abelhas coletadas, tendo sido coletada principalmente em forrageio a asteráceas. Apesar de inferências sobre uma possível competição com espécies nativas de abelhas, o impacto de A. mellifera tem sido considerado pequeno ou mesmo nulo (p. ex. Pedro \& Camargo 1991). Entretanto, o desaparecimento local de espécies sociais, como Melipona quinquefasciata, Schwarziana quadripunctata e Bombus bellicosus, pode estar diretamente relacionado à expansão da distribuição e abundância de $A$. mellifera em épocas recentes. Um possível efeito negativo e de forte impacto desta espécie poderia ser a redução na quantidade de néctar disponível para ser guardado como reserva de alimento pelos meliponíneos ou para ser transformado em reservas corporais nas rainhas de Bombus, diminuindo assim as chances de sobrevivência durante o inverno.

Perfil das coletas e das variações sazonais

O mês de novembro, embora apenas o sexto mês mais rico 
do levantamento, apresentou a maior equitabilidade (PEI = 0,98667). Cálculos de rarefação mostram que esse mês apresenta uma maior riqueza acumulada em amostras menores (Fig. 2). O reduzido número de espécies abundantes pode explicar este padrão, sendo que dentre as abelhas nativas somente Trigona spinipes teve mais que quatro indivíduos capturados (Apêndice I). Já março, que teve o maior número de espécies coletadas, apresentou uma equitabilidade menor $(0,9008)$ comparado a outros meses (novembro a fevereiro) e baixa riqueza esperada em pequenas amostras. A elevada abundância de algumas espécies (Rhophitulus aff. steinbachi, 42 e Rhophitulus sp.1, 17 indivíduos; Bombus atratus, 57; e Augochloropis sparsilis, 20) influenciou esses cálculos. Estes dados mostram profundas diferenças entre os meses de coleta, e mostram também que diferentes esforços podem comprometer os números de espécies encontrados.

Segundo sugestão de Cure et al. (1993), estimativas confiáveis da riqueza relativa poderiam ser produzidas a partir de amostragens parciais, envolvendo apenas os meses de maior atividade, ao invés de amostragens em todos os meses do ano. Estimando o número de espécies em uma sub-amostra de 388 indivíduos, esses autores encontraram (para uma determinada área) um número esperado de 86 espécies para os meses de novembro a março contra um número esperado de 87 espécies em todo os meses do ano. Em Vila Velha, o número de espécies esperado para este mesmo tamanho de amostra, nos meses em questão $(E 388=116)$, é superior ao número esperado para todos os meses $($ E388 $=113)$. Segundo esse critério, o conjunto de abelhas coletadas nesses meses, nos quais $80 \%$ do total de espécies foram amostradas, pode ser utilizado como indicador da composição de Vila Velha.

É importante ressaltar que A. mellifera apresentou uma marcada flutuação na sua abundância, variando desde $1 \%$ dos indivíduos coletados a quase $60 \%$ (Tabela II). As acentuadas flutuações apontam para um comportamento de preferência a floradas em massa, como também notado por Wilms et al. (1996), sendo que as áreas de mata próximas à área de coleta poderiam estar oferecendo tal situação. A riqueza esperada para o mês de dezembro mostra que a equitabilidade é altamente afetada pela presença de $A$. mellifera. Nas simulações sem essa espécie, a riqueza de dezembro foi claramente maior quando comparada com simulações em que A. mellifera foi considerada.

\section{Plantas visitadas}

A presença significativa de Asteraceae é comum a outras áreas brasileiras (Barbola et al. 2000, Faria-Mucci et al. 2003). Para explicar o alto número de visitas a essa família, alguns fatores têm sido mencionados por diferentes autores: a abundância e riqueza da família nos trópicos, a acessibilidade de coleta de recursos nas suas flores (Faria-Mucci et al. 2003), a sua disseminada síndrome entomófila, a dominância de suas ervas em campos secundários (Sakagami et al. 1967), e por fim a característica de apresentar floradas maciças.

O fato de Apiacaeae ser a segunda família mais rica e visitada pelas abelhas, só se assemelha à condição encontrada
Tabela III. As 10 famílias de plantas mais visitadas e gêneros representativos, analisados quanto ao número de espécies de plantas (Espécies); número de espécies (Esp. de abelhas) e de espécimes (Ind. de abelhas) de abelhas visitantes; e número de visitantes excluídas as visitas de Apis (Ind. excl. Apis).

\begin{tabular}{lcccc}
\hline \multicolumn{1}{c}{ Táxon } & Espécies & $\begin{array}{c}\text { Esp. de } \\
\text { abelhas }\end{array}$ & $\begin{array}{c}\text { Ind. de } \\
\text { abelhas }\end{array}$ & $\begin{array}{c}\text { Ind. excl. } \\
\text { Apis }\end{array}$ \\
\hline Asteraceae & 43 & 80 & 764 & 389 \\
$\quad$ Baccharis & 5 & 27 & 118 & 91 \\
$\quad$ Vernonia & 7 & 23 & 134 & 69 \\
$\quad$ Verbesina & 1 & 20 & 194 & 34 \\
$\quad$ Trixis & 1 & 21 & 57 & 31 \\
$\quad$ Eupatorium & 7 & 17 & 85 & 30 \\
Apiaceae & 3 & 36 & 159 & 154 \\
Fabaceae & 7 & 35 & 70 & 68 \\
$\quad$ Centrosema & 1 & 14 & 29 & 29 \\
$\quad$ Crotalaria & 2 & 10 & 23 & 22 \\
Rubiaceae & 3 & 20 & 61 & 42 \\
$\quad$ Borreria & 2 & 19 & 55 & 36 \\
Caesalpinaceae & 2 & 14 & 18 & 18 \\
Arecaceae & 2 & 13 & 44 & 38 \\
Malvaceae & 3 & 12 & 20 & 16 \\
Cactaceae & 1 & 9 & 27 & 27 \\
Anacardiaceae & 1 & 8 & 18 & 18 \\
Lamiaceae & 1 & 7 & 23 & 17 \\
\hline
\end{tabular}

em Lapa (Barbola et al. 2000), pois essa família não é expressiva nos demais estudos brasileiros. Eryngium foi o gênero mais visitado pelas abelhas nativas, fato que pode ser explicado pela acentuada facilidade de acesso aos seus recursos florais (característica presente também em Asteraceae).

A presença de três espécies de Malpighiaceae, em particular as duas de Byrsonima, chama atenção quando se compara com outros estudos conduzidos em áreas abertas no sul do Brasil. Com exceção de Guaritas, RS, onde uma espécie de Janusia A. Juss. estava presente (Schlindwein 1995), nenhuma Malpighiaceae aparece listada nos outros levantamentos. Deste modo, as relações entre abelhas coletoras de óleo e suas fontes reforçam a similaridade entre a área de campo estudada aqui com o cerrado.

Foi sugerido por Silveira \& Campos (1995) que a maior riqueza e especialização de espécies de abelhas no cerrado poderiam estar associadas à maior riqueza e a maior diversificação taxonômica da flora. O critério de riqueza utilizado foi o número esperado de espécies para uma amostra de 400 indivíduos (E400). Em São José dos Pinhais, único representante de campos naquele estudo, o E400 foi mais baixo que para o cerrado, apesar do maior número de espécies coletadas.

Em Vila Velha tanto a riqueza de espécies e o número de espécies esperado em uma amostra de 400 indivíduos (115) quanto a riqueza de plantas são superiores aos números apresentados para o cerrado, mas $41 \%$ das plantas são asteráceas, sinal de baixa diversificação segundo aqueles autores. Portanto, de acordo com os resultados aqui obtidos, a riqueza de abelhas estaria mais diretamente relacionada com a riqueza de plantas e em menor grau com a diversificação taxonômica. 
Tabela IV. Plantas secretoras de óleo e suas abelhas coletoras associadas. $\mathrm{N}$ = número de espécimes capturados.

\begin{tabular}{|c|c|c|c|c|}
\hline \multicolumn{2}{|r|}{ Planta } & \multicolumn{3}{|c|}{ Abelha } \\
\hline Família & Espécie & Tribo & Espécie & $\mathrm{N}$ \\
\hline \multirow{8}{*}{ Malpighiaceae } & Aspicarpa pulchella & Centridini & Centris (Hemisiella) tarsata & 1 \\
\hline & & Tapinotaspidini & P. (Lophopedia) sp.1 & 1 \\
\hline & Byrsonima brachybotrya & Tapinotaspidini & P. (Paratetrapedia) sp.2 & 1 \\
\hline & & “ & P. (Xanthopedia) iheringii & 3 \\
\hline & & “ & Arhysoceble xanthopoda & 1 \\
\hline & Byrsonima psilandra & Centridini & Centris (Paracentris) burgdorfi & 1 \\
\hline & & Tapinotaspidini & Arhysoceble xanthopoda & 2 \\
\hline & & “ & P. (Xanthopedia) iheringii & 1 \\
\hline Schrophulariaceae & Angelonia integerrima & “ & Arhysoceble xanthopoda & 1 \\
\hline
\end{tabular}

\section{Análise Qualitativa dos Grandes Grupos}

Andreninae. Este grupo apresenta maior riqueza e abundância em áreas semi-áridas temperadas, com um nítido gradiente ao longo do eixo norte-sul (Michener 2000). No Brasil, está praticamente ausente nas florestas da bacia amazônica (presentes apenas Chaeturginus e Oxaea), apresentando maior riqueza no extremo sul do país [p. ex. 28 espécies, em 7 gêneros, em estepe arbustiva no Rio Grande do Sul (Schlindwein 1995)]. A tribo Protandrenini é representada em Vila Velha por três gêneros, Anthrenoides (5 espécies), Psaenythia (4) e Rhophitulus (8) um padrão semelhante ao encontrado em outros levantamentos realizados no Paraná. Callonychium petuniae foi a única representante de Calliopsini, estando Vila Velha dentro do limite norte da espécie (o registro mais ao norte conhecido é Tibagi, PR, a cerca de 80 km a NO de Vila Velha, em áreas de transição entre cerrado e vegetação rupestre). A presença de Oxaea, um gênero até então não amostrado em levantamentos paranaenses, coloca Vila Velha em uma posição diferenciada. Três espécies são conhecidas em Vila Velha, O. austera Gerstäcker, O. mourei Graf (Graf 1982) e O.flavescens, sendo que apenas esta última foi coletada no presente levantamento. Espécies de Acamptopoeum e Parapsaenythia não foram encontradas. Embora um artefato no presente caso, uma vez que um espécime macho já foi previamente coletado no Parque, a ausência de Acamptopoeum parece refletir também uma reduzida abundância na região.

Apinae. De maneira semelhante a Megachilinae, e diferentemente das outras três subfamílias, os Apinae como um todo, não exibem um gradiente latitudinal de riqueza na América do Sul, embora este gradiente possa ser detectado em muitos dos subgrupos (tribos e subtribos). O número de espécies de Apini está em acordo com aqueles encontrados nos demais levantamentos conduzidos no estado, nos quais, em média, seis espécies de abelhas corbiculadas estão presentes. Trata-se de um grupo pouco diversificado no sul do país, especialmente em áreas abertas. As cinco espécies de meliponíneos encontradas fazem seus ninhos em ocos de árvores ou presos a galhos (T. spinipes) e, portanto, sua presença no campo deve-se a operárias forrageando fora das áreas de floresta adjacentes. Inclusive, o baixíssimo número de indivíduos de Melipona, Plebeia e Tetragonisca sugere que suas espécies forrageiam no campo apenas ocasionalmente. Curiosamente, espécies que nidificam no solo não foram encontradas, apesar de existirem registros históricos (espécimes da coleção DZUP coletados na década de 1960) para Melipona quinquefasciata Lepeletier e Schwarziana quadripunctata (Lepeletier). Outra espécie que parece ter desaparecido localmente é Bombus bellicosus Smith. Há registros históricos para Vila Velha e arredores (Moure \& Sakagami 1962).

Tanto Centris como Epicharis (Centridini) apresentam elevada riqueza em áreas de florestas (atlântica e amazônica) e cerrado. No Paraná, duas espécies de Centris, em média, têm sido encontradas nos levantamentos, ao passo que em Vila Velha foram capturadas seis espécies. De um modo geral as espécies presentes em Vila Velha exibem uma ampla distribuição, com exceção de $C$. (Melacentris) xanthocnemis que era apontada (Silveira et al. 2002) como presente somente nos estados de MG, MT e SP. Dentre as duas espécies de Epicharis, E. iheringi era conhecida somente para áreas de cerrado (Gaglianone 2001), ao passo que Epicharis grandior apresenta ampla distribuição.

De Emphorini foram coletadas as espécies Ancyloscelis romeroi, Melitoma segmentaria e Ptilothrix plumata. Essa tribo é mais rica nos levantamentos do Rio Grande do Sul. Dois gêneros, Diadasina e Alepidosceles, presentes em áreas com vegetação aberta, não foram encontrados. De Eucerini, apenas as espécies Melissoptila richardiae, M. minarum e Thygater mourei foram capturadas, porém outras espécies já foram coletadas em outras áreas dentro do Parque.

Sete espécies de Tapinotaspidini foram coletadas. Essa tribo apresenta maior diversidade em áreas de cerrado e de mata atlântica, sendo a riqueza aqui encontrada relativamente alta para estudos em campos. Duas espécies, Arhysoceble xanthopoda e $P$. (Paratetrapedia) sp.1, eram conhecidas até então como presentes somente em áreas de cerrado. Outras espécies coletadas dessa tribo foram Lanthanomelissa aff. clementis, Paratetrapedia (Lophopedia) pygmaea, P. (Lophopedia) sp.1, P. (Xanthopedia) iheringii e Tapinotaspoides serraticornis. Espécies adicionais coletadas na área em outras ocasiões foram: Caenonomada labrata 
Zanella, 2003, Monoeca cfr. lanei (Moure, 1944), P. (Paratetrapedia) maculata (Friese, 1899), P. (Paratetrapedia) fervida (Smith, 1879) e Trigonopedia sp.

$\mathrm{Na}$ tribo Xylocopini (Xylocopinae sensu Silveira et al. 2002), Ceratina foi encontrada em todas as coletas, possuindo muitos indivíduos, sobretudo no mês de maio quando outros grupos de abelhas estavam ausentes. A sua alta riqueza (12 espécies) está de acordo com outros trabalhos conduzidos no sul e sudeste do país, porém o gênero carece de revisões taxonômicas. Xylocopa também é um gênero rico com presença marcante nos estudos brasileiros. Com exceção de X. augusti e $X$. bimaculata que só foram capturadas em uma coleta (outubro), as demais espécies foram relativamente abundantes, sobretudo X. ciliata (Apêndice I).

Cabe salientar a presença de espécies cleptoparasitas em Vila Velha. A dependência de um hospedeiro para a sua reprodução torna a população de cleptoparasitas frágil, visto que as taxas de parasitismo são dependentes da densidade e dependem de uma sincronia ontogenética entre os ciclos dos parasitas e hospedeiros (Wcislo 1987). Estudos de monitoramento de fauna indicam que, com a degradação do ambiente, as populações dos grupos parasitas sofrem reduções e, até mesmo, extinções locais (Laroca \& Orth 2002). Foram encontrados no PEVV seis apíneos parasitas: Ctenioschelus goryi e Mesonychium caerulescens (Ericrocidini), Nomada sp.1 (Nomadini), Osirinus santiagoi, O. sp.1 e Parepeolus aterrimus (Osirini). A diversidade encontrada é equivalente àquela observada na maioria dos estudos conduzidos em áreas de cerrado e maior do que a de outras áreas abertas no Paraná.

Colletinae. Duas espécies de Colletes, C. rugicollis e $C$. sp.1, foram os representantes da tribo Colletini em Vila Velha. Dentre os Paracolletini somente Hexantheda missionica, que voou em outubro forrageando em Callibrachoa rupestris, foi encontrada. Nomiocolletes e Perditomorpha, gêneros de Paracolletini, além do Diphaglossini Ptiloglossa, já foram coletados em outras oportunidades no Parque. A relativa pobreza de Colletini e Paracolletini contrasta com a diversidade de Hylaeini e Xeromelissini. O gênero Hylaeus está representado por 10 espécies e Chilicola por cinco sendo uma delas pertencente ao subgênero Prosopoides e quatro a Oediscelis (apenas uma já descrita, C. dalmeidai). Esse último gênero esteve constantemente relacionado com Eryngium e aparece nos levantamentos em campos e na mata atlântica, bem como Hylaeus.

Halictinae. A alta freqüência de Halictinae nos levantamentos no sul do país parece ser devido a uma característica de comunidades de hábitat de vegetação aberta e/ou secundária (Barbola \& Laroca 1993). Augochlorini apresentou 32 espécies e Halictini 26 espécies, sendo que esses números se devem principalmente aos gêneros Augochlora, Augochloropsis e Dialictus que além de possuírem alto número de espécies, possuem populações densas.

Pseudagapostemon é relacionado por Michener (1979) como característico do sul temperado da América. No PEVV foram encontradas as espécies $P$. anasimus, $P$. cyaneus e $P$. ochromerus. As duas últimas são espécies com ampla distribuição enquanto a primeira era dada como restrita ao sudeste e centro-oeste brasileiros. Pseudagapostemon tesselatus foi coletada em 07 de dezembro de 2002, coleta descartada, e em outras oportunidades. Os registros dessa espécie sugerem que esteja associada ao cerrado. Outra espécie presente em Vila Velha, porém não amostrada no presente levantamento, é Oragapostemon divaricatus (Vachal, 1904).

Megachilinae. Anthidiini possui poucos representantes amostrados nos levantamentos paranaenses, exceto aqui onde sete espécies foram encontradas. Ananthidium dilmae era conhecido somente de Minas Gerais e foi coletado em março. Anthidium sertanicola (setembro e dezembro) também não era conhecido para o estado e aparentemente têm distribuição restrita a áreas de cerrado. As demais espécies foram Anthodioctes claudii, Dicranthidium gregarium, Hypanthidioides flavofasciatum, Moureanthidium catarinense e Saranthidium musciforme. Em Megachilini foram encontradas 20 espécies de Megachile e apenas três espécies do gênero cleptoparasita Coelioxys. Megachile (Leptorachis) friesei era conhecida somente para os estados de Minas Gerais e São Paulo (Silveira et al. 2002).

\section{Comparações com faunas de outros ambientes com} vegetação aberta

Os campos nativos do Paraná, incluindo a região onde se encontra o Parque de Vila Velha, têm sido considerados como parte das estepes sulinas (p. ex. Roderjan et al. 2002; Ziller 2000). A presença de espécies como Callonychium petuniae, Rhophitulus reticulatus, Centris (Trachina) proxima, Xylocopa (Nanoxylocopa) ciliata, Hexantheda missionica, Chilicola (Oediscelis) spp. e Oragapostemon divaricatus dá suporte a este padrão. Por outro lado, a presença de abelhas que eram anteriormente conhecidas apenas para o cerrado, como Arhysoceble xanthopoda, Caenonomada labrata, Epicharis iheringi, Melipona quinquefasciata, Paratetrapedia sp.1 e Pseudagapostemon tesselatus, apontam para a ligação dos campos de Vila Velha com o cerrado. Tanto Arhysoceble xanthopoda e Epicharis iheringi foram também encontradas no cerrado de Jaguariaíva, norte do estado (Almeida 2003). Ziller (2000) reconhece a presença de espécies de plantas típicas de cerrado em Vila Velha, embora nenhuma destas espécies tenha sido encontrada na área de estudo.

Estudos palinólogicos mostram que as áreas ocupadas por campos e por cerrados no Paraná eram maiores no passado recente, tendo havido expansão da floresta de Araucaria sobre as áreas abertas apenas com o estabelecimento de um clima mais úmido na região a partir de 3.000 anos atrás (Behling 1997; Ledru et al. 1998). Áreas com sobreposição e contato entre as formações abertas devem ter sido mais extensas no passado, tornando possível um maior intercâmbio das faunas de abelhas. A composição da fauna de abelhas de Vila Velha pode ser considerada como um testemunho deste intercâmbio. 
Agradecimentos. A Antônio J. C. Aguiar pelo incentivo e pelo auxílio nas coletas; a Olavo Araújo Guimarães, Gert Hatschbach e Renato Goldenberg pela identificação das plantas; à Profa. Danúncia Urban pela identificação dos Anthidiini e Eucerini; ao CNPq e a ao Tesouro Nacional/UFPR pelas bolsas de iniciação científica e de produtividade em pesquisa; e ao Instituto Ambiental do Paraná (IAP) por fornecer autorização de coleta de abelhas e plantas no PEVV.

\section{REFERÊNCIAS}

Almeida, M. C. 2003. Taxonomia e Biocenótica de Apoidea (Hymenoptera) de Áreas Restritas de Cerrado no Município de Jaguariaíva, Paraná, Sul do Brasil. Tese de Doutorado. Universidade Federal do Paraná. 206 p.

Alves-dos-Santos, I. 1999. Abelhas e plantas melíferas da mata atlântica, restinga e dunas do litoral norte do estado do Rio Grande do Sul, Brasil. Revista Brasileira de Entomologia 43: 191-223.

Barbola, I. F. \& S. Laroca. 1993. A comunidade de Apoidea (Hymenoptera) da Reserva Passa Dois (Lapa, Paraná, Brasil): 1. Diversidade, abundância relativa e atividade sazonal. Acta Biológica Paranaense 22: 91-113.

Barbola, I. F.; S. Laroca \& M. C. Almeida. 2000. Utilização de recursos florais por abelhas silvestres (Hymenoptera, Apoidea) da Floresta Estadual Passa Dois (Lapa, Paraná, Brasil). Revista Brasileira de Entomologia 44: 9-19.

Behling, H. 1997. Late quaternary vegetation, climate and fire history of the Araucaria Forest and campos region from Serra Campos Gerais, Paraná State (South Brazil). Review of Palaeobotany and Palynology 97: 109-121.

Bortoli, C. \& S. Laroca. 1990. Estudo biocenótico em Apoidea (Hymenoptera) de uma área restrita em São José dos Pinhais (PR, Sul do Brasil), com notas comparativas. Dusenia 15: 1-112.

Bortoli, C. \& S. Laroca. 1997. Melissocenologia no Terceiro Planalto Paranaense. I: Abundância relativa das abelhas silvestres (Apoidea) de um biótopo urbano de Guarapuava (PR, Brasil). Acta Biológica Paranaense 26: $51-86$.

Cure, J. R.; G. S. Bastos Filho; M. J. F. de Oliveira \& O. F. de Souza. 1993. Influência do tamanho da amostra na estimativa da riqueza em espécies em levantamentos de abelhas silvestres (Hymenoptera, Apoidea). Revista Brasileira de Zoologia 7: 101-110.

Faria-Mucci, G. M.; M. A. Melo \& L. A. O. Campos. 2003. A fauna de abelhas (Hymenoptera, Apoidea) e plantas utilizadas como fonte de recursos florais, em um ecossistema de campos rupestris em Lavras Novas, Minas Gerais, Brasil, p. 241-256. In: G. A. R. Melo \& I. Alves-dos-Santos (eds.). Apoidea Neotropica: Homenagem aos 90 Anos de Jesus Santiago Moure. Criciúma, Editora UNESC, $320 \mathrm{p}$.

Gaglianone, M. C. 2001. Bionomia de Epicharis, Associações com Malpighiaceae e uma Análise Filogenética e Biogeográfica das Espécies dos Subgêneros Epicharis e Epicharana (Hymenoptera, Apidae, Centridini). Tese de Doutorado. Universidade de São Paulo. Ribeirão Preto.

Gotelli, N. J. \& G. L. Entsminger. 2005. EcoSim: Null models software for ecology. Version 7. Acquired Intelligence Inc. \& Kesey-Bear. Jericho, VT 05465. http://garyentsminger.com/ecosim.htm. Acessado em 24 de novembro de 2005

Graf, V. 1993. Uma nova espécies de Oxaea Klug (Oxaeinae, Andreninae, Hymenoptera) do sul do Brasil. Revista Brasileira de Zoologia 9: 153-155.

Hoffmann, M. 1990. Estrutura e Importância de uma Comunidade de Abelhas no Rio Grande do Sul, para a Polinização de Plantas Cultivadas. Tese de doutorado. Universidade Federal do Paraná. 117 p.

Hurlbert, S. H. 1971. The non-concept of species diversity: a critique and alternative parameters. Ecology 52: 577-586.

Klein, R. M. \& G. Hatschbach. 1971. Fitofisionomia e notas complementares sobre o mapa fitogeográfico de Quero-Quero (Paraná). Boletim Paranaense Geociências 28/29: 159-188.

Laroca, S. \& A. I. Orth. 2002. Melissocenology; historical perspective. Method of sampling, and recommendations to the "program of conservation and sustainable use of pollinators, with emphasis on bees" (ONU). In: P. G. Kevan \& V. L. Imperatriz-Fonseca. (eds).
Pollinating Bees: The Conservation Link between Agriculture and Nature. Brasilia, Ministry of Environment. $313 \mathrm{p}$.

Ledru, M. P., M. L. Salgado-Labouriau \& M. L. Lorscheitter. 1998. Vegetation dynamics in southern and central Brazil during the last 10,000 yr B.P. Review of Palaeobotany and Palynology 99: $131-142$

Melo, G. A. R. \& R. B. Gonçalves. 2005. Higher-level bee classifications (Hymenoptera, Apoidea, Apidae sensu lato). Revista Brasileira de Zoologia 22: 153-159.

Michener, C. D. 1979. Biogeography of the bees. Annals of the Missouri Botanical Garden 66: 277-317.

Michener, C. D. 2000. The Bees of the World. Baltimore, Johns Hopkins University Press, xiv+913 p.

Moure, J. S. \& S. F. Sakagami. 1962. As mamangavas sociais do Brasil (Bombus Latr.) (Hym. Apoidea). Studia Entomologica 5: 65194.

Pedro, S. R. M. \& J. M. F. Camargo. 1991. Interactions on floral resources between the Africanized honey bee Apis mellifera $\mathrm{L}$ and the native bee community (Hymenoptera: Apoidea) in a natural "cerrado" ecosystem in southeast Brazil. Apidologie 22: 397415.

Roderjan, C. V.; F. Galvão; Y. S. Kuniyoshi \& G. G. Hatschbach. 2002. As unidades fitogeográficas do Estado do Paraná. Ciência e Ambiente 24: 75-92.

Sanders, H. L. 1968. Marine benthic diversity: a comparative study. American Naturalist 102: 243-282.

Sakagami, S. F.; S. Laroca \& J. S. Moure. 1967. Wild bee biocoenotics in São José do Pinhais (PR), South Brazil. Preliminary report. Journal of the Faculty of Science, Hokkaido University [Series VI, Zoology] 16: 253-291.

Schlindwein, C. 1995. Wildbienen und ihre Trachtpflanzen in einer südbrasilianischen Buschlandschaft: Fallstudie Guaritas, Bestäubung bei Kakteen und Loasaceen. Tese de Doutorado, Ebehhard-Karls Universität, Tübingen, Alemanha. 148p.

Silveira, F. A.; G. A. R. Melo \& E. A. B. Almeida. 2002. Abelhas Brasileiras: Sistemática e Identificação. Belo Horizonte, Fernando A. Silveira. 253 p.

Silveira, F. A. \& M. J. O. Campos. 1995. A melissofauna de Corumbataí (SP) e Paraopeba (MG) e uma análise da biogeografia das abelhas do cerrado brasileiro (Hymenoptera, Apoidea). Revista Brasileira de Entomologia 39: 371-401.

Silveira, F. A. \& L. M. Godínez. 1996. Systematic surveys of local bee faunas. Melissa 9: 1-4.

Simberloff, D. S. 1972. Properties of the rarefaction diversity measurement. American Naturalist 106: 414-418.

Takeda, I. J. M \& P. V. Faraco. 2001. Vegetação do Parque Estadual de Vila Velha. Guia de Campo, volume 1. Curitiba, I. J. M. Takeda. 419 p.

Taura, H. M. \& S. Laroca. 2001. A associação de abelhas silvestres de um biótopo urbano de Curitiba (Brasil), com comparações espaçotemporais: abundância relativa, fenologia,diversidade e explotação de recursos (Hymenoptera, Apoidea). Acta Biológica Paranaense 30: $35-137$

Ziller, S. R. 2000. A Estepe Gramíneo-Lenhosa no Segundo Planalto do Paraná: Diagnóstico Ambiental com Enfoque à Contaminação Biológica. Tese de Doutorado. Universidade Federal do Paraná. $268 \mathrm{p}$.

Wcislo, W. T. 1987. The roles of seasonality, host synchrony, and behavior in the evolutions and distributions of nest parasites in Hymenoptera (Insecta), with special reference to bees (Apoidea). Biological Reviews 62: 515-543.

Wilms, W., V. L. Imperatriz-Fonseca \& W. Engels. 1996. Resource partitioning between highly eusocial bees and possible impact of the introduced Africanized honey bee on native stingless bees in the Brazilian Atlantic Rainforest. Studies on Neotropical Fauna \& Environment 31: 137-151.

Wittmann, D., R. Radtke, J. R. Cure \& M. T. Schifino-Wittmann. 1990. Coevolved reproductive strategies in the oligolectic bee Callonychium petunie (Apoidea, Andrenidae) and three purple flowered Petunia species (Solanaceae) in southern Brazil. Zeitschrift für Zoologische Systematik und Evolutionsforschung 28: 157-165. 


\section{APÊNDICE}

Apêndice I. Lista das espécies de abelhas coletadas em uma área restrita de campo natural no Parque Estadual de Vila Velha, no período de outubro de 2002 a outubro de 2003 exceto junho a agosto de 2003. $\mathrm{N}$ = código da espécie; $\mathrm{M}$ = número de machos; $\mathrm{F}=$ número de fêmeas. Os números na coluna 'Planta' referem-se ao código das espécies de plantas visitadas (vide Apêndice II).

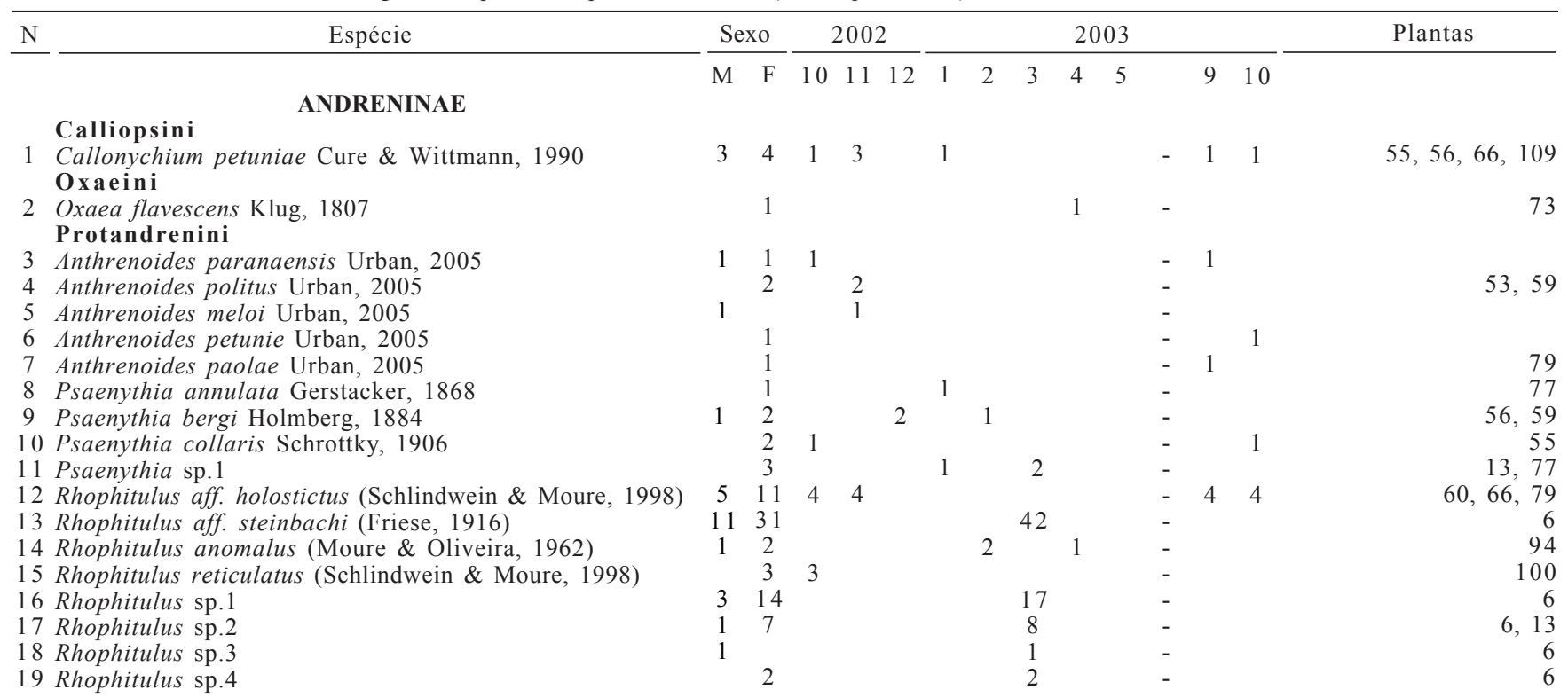

\section{Anthophorini}

20 Anthophora paranaensis Holmberg, 1903 Apini

21 Apis mellifera Linnaeus, 1758
1

23 Bombus (Fervidobombus) morio (Swederus, 1787)

24 Eufriesea violacens (Mocsáry, 1898)

25 Melipona quadrifasciata Lepeletier, 1836

26 Plebeia emerina (Friese, 1900)

27 Scaptotrigona bipunctata (Lepeletier, 1836)

28 Tetragonisca angustula (Latreille, 1811)

29 Trigona spinipes (Fabricius, 1793) Centridini

30 Centris (Hemisiella) tarsata Smith, 1874

31 Centris (Melacentris) sp. 1

32 Centris (Melacentris) xanthocnemis (Perty, 1833)

33 Centris (Paracentris) burgdorfi Friese, 1900

34 Centris (Trachina) proxima Friese, 1899

35 Centris (Xanthemisia) bicolor Lepeletier, 1841

36 Epicharis (Epicharitides) iheringi Friese, 1899

37 Epicharis (Epicharoides) grandior (Friese, 1899) Emphorini

38 Ancyloscelis romeroi (Holmberg, 1903)

39 Melitoma segmentaria (Fabricius, 1804)

40 Ptilothrix plumata Smith, 1853 Ericrocidini

41 Ctenioschelus goryi (Romand, 1840)

42 Mesonychium caerulescens Lepeletier \& Serville, 1825 Eucerini

43 Melissoptila minarum (Bertoni \& Schrottky, 1910)

44 Melissoptila richardiae Bertoni \& Schrottky, 1910

45 Thygater mourei Urban, 1961 Exomalopsini

46 Exomalopsis (Exomalopsis) analis Spinola, 1850

47 Exomalopsis (Phanomalopsis) sp.1
2

2

$43430211104111191320 \quad-\quad 6 \quad 1 \quad 6,9,11,12,14,15,18$, $20,22,23,24,26,33$, $37,38,41,43,44,45$ $50,51,59,62,66,71$, $74,77,79,84,85,91$ $96,102,103,104,113$ $6,7,13,17,44,46,47$,

$50,51,57,58,63,73$ $91,103,112$ 17, 44, 45, 49, 56, 73, $91,101,112$

$4,6,9,14,15,26,34$ $43,65,68,69,74$ $9,15,56,74$

87 $18,44,73,74$ 12,74 12,74
89 73,74 73 112 108

$49,55,66,67,90$ 67 6, 92

1

6 3 
Apêndice I. Continuação.

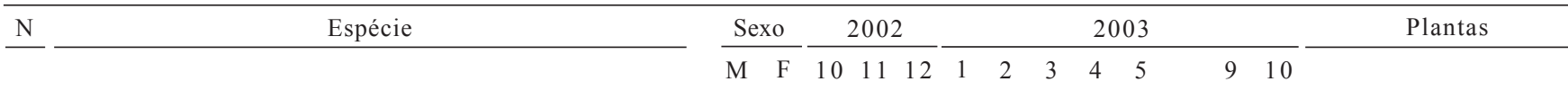

Nomadini

48 Nomada sp. 1

Osirini

49 Osirinus santiagoi (Almeida, 1996)

50 Osirinus sp. 1

51 Parepeolus aterrimus (Friese, 1906)

Tapinotaspidini

52 Arhysoceble xanthopoda Moure, 1948

53 Lanthanomelissa aff. clementis Urban, 1995

54 Paratetrapedia (Lophopedia) pygmaea (Schrottky, 1902)

55 Paratetrapedia (Lophopedia) sp.1

56 Paratetrapedia (Paratetrapedia) sp.1

57 Paratetrapedia (Xanthopedia) iheringii (Friese, 1899)

58 Tapinotaspoides serraticornis (Friese, 1899)

Tetrapedini

59 Tetrapedia sp. 1

Xylocopini

60 Ceratina (Ceratinula) biguttulata (Moure, 1941)

61 Ceratina (Ceratinula) sp.1

62 Ceratina (Crewella) rupestris Holmberg, 1884

63 Ceratina (Crewella) sp.1

64 Ceratina (Crewella) sp.2

65 Ceratina (Crewella) sp.3

66 Ceratina (Crewella) sp.4

67 Ceratina (Crewella) sp.5

68 Ceratina (Crewella) sp.6

69 Ceratina (Rhysoceratina) sp.1

70 Ceratina (Rhysoceratina) sp.2

71 Ceratina (Rhysoceratina) sp.3

72 Xylocopa (Dasyxylocopa) bimaculata Friese, 1903

73 Xylocopa (Nanoxylocopa) ciliata Burmeister, 1876

74 Xylocopa (Neoxylocopa) augusti Lepeletier, 1841

75 Xylocopa (Neoxylocopa) frontalis (Olivier, 1789)

76 Xylocopa (Stenoxylocopa) artifex Smith, 1874

\section{Colletini}

77 Colletes rugicollis Friese, 1900

78 Colletes sp. 1

Hylaeini

79 Hylaeus (Hylaeopsis) aff. binus (Vachal, 1910)

80 Hylaeus (Hylaeopsis) culiciformis (Schrottky, 1906)

81 Hylaeus (Hylaeopsis) gracillimus (Schrottky, 1902)

82 Hylaeus (Hylaeopsis) sp.1

83 Hylaeus (Hylaeopsis) sp.2

84 Hylaeus (Hylaeopsis) sp.3

85 Hylaeus (Hylaeopsis) sp.4

86 Hylaeus (Hylaeopsis) sp.5

87 Hylaeus (Hylaeopsis) sp.7

$$
\text { Paracolletini }
$$

88 Hexantheda missionica Ogloblin, 1948

Xeromellissini

89 Chilicola (Oediscelis) dalmedai (Moure, 1948)

90 Chilicola (Oediscelis) sp.1

91 Chilicola (Oediscelis) sp.2

92 Chilicola (Oediscelis) sp. 3

93 Chilicola (Prosopoides) sp.1

\section{HALICTINAE}

\section{Augochlorini}

94 Augochlora amphitrite (Schrottky, 1909)

95 Augochlora cydippe (Schrottky, 1910)

96 Augochlora daphnis Smith, 1853

97 Augochlora dolichocephala (Moure, 1941)

98 Augochlora foxiana Cockerell, 1900

99 Augochlora semiramis (Schrottky, 1910)

100 Augochloropsis aff. cyanea (Schrottky, 1902)

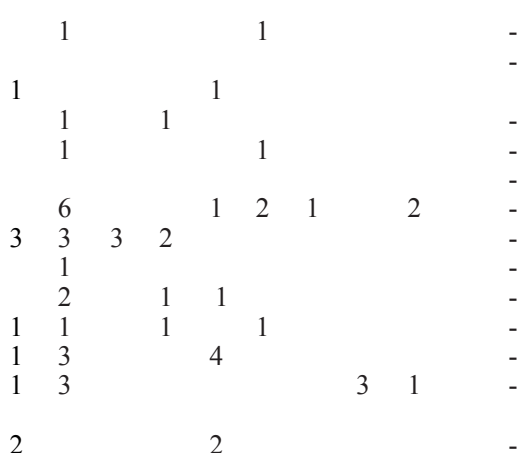

$78,88,89,90,107$ $59,81,82,86,100$

45
88

88
88

88,89

90,103

43

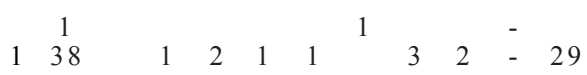

$30,42,45,78$

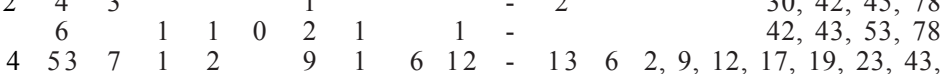

$44,45,47,48,49$

$\begin{array}{llllll}1 & 8 & 3 & 3 & - & 3\end{array}$

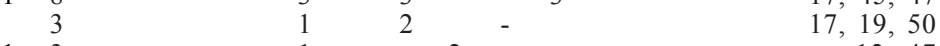

12,47

17

$19,30,36,44,45,48$,

$51,53,55,58,59,66$,

79,109

$\begin{array}{rrrrrrr}2 & 1 & & 1 & - & 26,30 \\ 1 & & 1 & & - & & 59\end{array}$

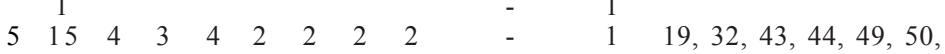

$51,73,75,85$

75
73

73

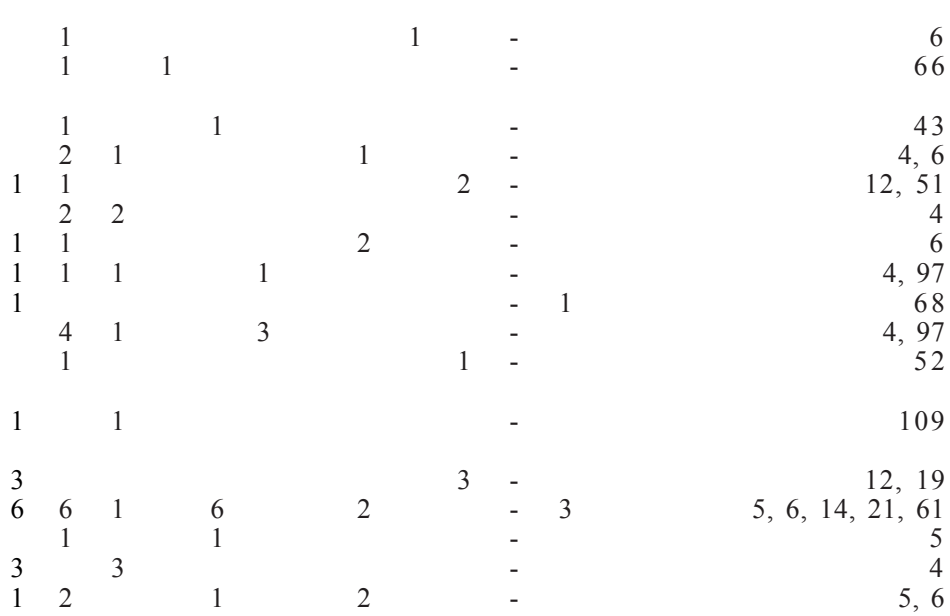

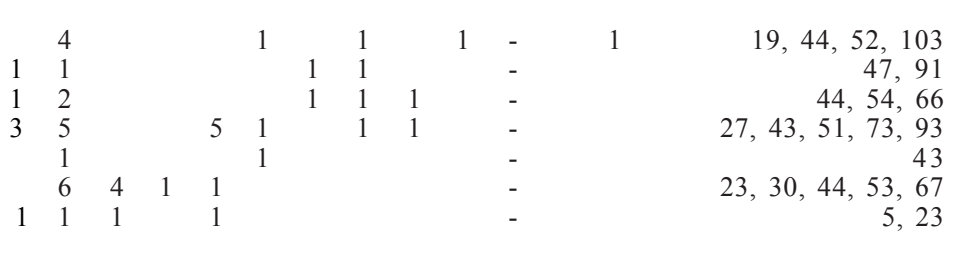


Apêndice I. Continuação.

$\mathrm{N}$
101 Augochloropsis anisitsi (Schrottky, 1908)
102 Augochloropsis cleopatra (Schrottky, 1902)

103 Augochloropsis deianira (Schrottky, 1910)

104 Augochloropsis aff. cognata Moure, 1944

105 Augochloropsis multiplex (Vachal, 1903)

106 Augochloropsis rotalis (Vachal, 1903)

107 Augochloropsis semele (Schrottky, 1902)

108 Augochloropsis simpleres (Vachal, 1902)

109 Augochloropsis sparsilis (Vachal, 1903)

110 Augochloropsis sp.1

111 Augochloropsis sp.2

112 Augochloropsis sp. 3

113 Augochloropsis sp.4

114 Augochloropsis sp.5

115 Ceratalictus clonius (Brèthes, 1909)

116 Ceratalictus sp. 1

117 Ceratalictus stigon (Vachal, 1911)

118 Paroxystoglossa andromache (Schrottky, 1909)

119 Paroxystoglossa jocasta (Schrottky, 1910)

120 Paroxystoglossa sp.1

121 Paroxystoglossa sp.2

122 Paroxystoglossa sp.3

123 Pseudaugochlora sp.1

124 Rhynocorynura aff. inflaticeps (Ducke, 1906)

125 Thectochlora basiatra (Strand, 1910)

Halictini

126 Agapostemon chapadensis Cockerell, 1900

127 Caenohalictus sp.1

128 Caenohalictus tesselatus (Moure, 1940)

129 Dialictus micheneri (Moure, 1956)

130 Dialictus rostratus (Moure, 1947)

131 Dialictus sp. 1

132 Dialictus sp.2

133 Dialictus sp.3

134 Dialictus sp.4

135 Dialictus sp. 5

136 Dialictus sp.6

137 Dialictus sp.7

138 Dialictus sp. 8

139 Dialictus sp.9

140 Dialictus sp.10

141 Dialictus sp.11

142 Dialictus sp.12

143 Dialictus sp.13

144 Dialictus sp.14

145 Dialictus sp.15

146 P. (Pseudagapostemon) anasimus Cure, 1987

147 P. (Pseudagapostemon) cyaneus Moure \& Sakagami, 19841

148 P. (Pseudagapostemon) ochromerus (Vachal, 1904)

149 Sphecodes sp.1

150 Sphecodes sp. 2

151 Sphecodes sp.3

\section{Anthidiini}

152 Ananthidium dilmae Urban, 1991

153 Anthidium sertanicola Moure \& Urban, 1964

154 Anthodioctes claudii Urban, 1999

155 Dicranthidium gregarium (Schrottky, 1905)

156 Hypanthidioides flavofasciatum (Schrottky, 1902)

157 Moureanthidium catarinense Urban, 1995

158 Saranthidium musciforme (Schrottky, 1902)

Megachilini

159 Coelioxys (Acrocoelioxys) tolteca Cresson, 1878

2

\begin{tabular}{|c|c|c|c|c|c|c|c|c|c|c|c|c|}
\hline \multicolumn{2}{|c|}{ Sexo } & \multicolumn{3}{|c|}{2002} & \multicolumn{8}{|c|}{2003} \\
\hline M & $\mathrm{F}$ & 10 & 11 & 12 & 1 & 2 & 3 & 4 & 5 & & 9 & 10 \\
\hline \multirow[t]{4}{*}{2} & 3 & & 1 & & & & 4 & & & - & & \\
\hline & 2 & 1 & 1 & & & & & & & - & & \\
\hline & 3 & 1 & 1 & & 1 & & & & & - & & \\
\hline & 3 & & & & 2 & 1 & & & & - & & \\
\hline \multirow[t]{3}{*}{3} & 4 & 2 & & 3 & & & 1 & & & - & & 1 \\
\hline & 1 & 1 & & & & & & & & - & & \\
\hline & 1 & & & & 1 & & & & & - & & \\
\hline 5 & 8 & 2 & & 2 & 2 & & & & & - & & 7 \\
\hline 15 & 26 & & & 5 & 7 & 9 & 20 & & & - & & \\
\hline
\end{tabular}

Plantas

$6,43,54,57$

$3,53,104$

56

$12,13,14,51,70,104$

$57,60,74,89,94$

$66,12,13,15,26,28$,

$30,34,43,54,62,97$,

$\begin{array}{cc}2 & \\ & 2 \\ & 1 \\ 7 & 18\end{array}$

$\begin{array}{lllllllll}17 & 18 & 2 & 1 & 2 & 23 & 2 & 1 & 1\end{array}$

1

$\begin{array}{lccccc}1 & & & 1 & & \\ 4 & 11 & 3 & 6 & 1 & 4 \\ 1 & 3 & 1 & 1 & & 2\end{array}$

$\begin{array}{lllllll}8 & 18 & 3 & 4 & 5 & 3 & 1\end{array}$

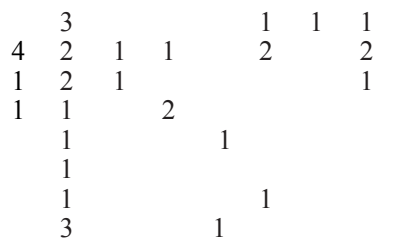

$1 \quad 10 \quad 1 \quad 4$

$\begin{array}{lllllll}1 & 6 & 2 & 1 & 1 & 1 & -2\end{array}$

$\begin{array}{cccccccc}1 & 1 & & & & 1 & & \\ 1 & 20 & 4 & 2 & 3 & 1 & 6 & 1\end{array}$

$\begin{array}{lllllllllll}1 & 1 & 0 & 2 & 1 & 2 & 1 & 1 & 1 & - & 1\end{array}$

$104,109,11$

$19,44,53$

10

15,104

15

6,7

79

2
20
$20,7,8,12,15,55,56,104,105$

$68,69,99,103,104$

105,111

$32,78,103$

10
103

$12,15,35,93$

5,56

17,45

37

$6,19,23,27,30,44$,

53,73

5,14

6, 12 
Apêndice I. Continuação.

\begin{tabular}{|c|c|c|c|c|c|c|c|c|c|c|c|c|c|}
\hline Espécie & & xo & & 2002 & & & & & & 03 & & & Plantas \\
\hline & M & $\mathrm{F}$ & 10 & 11 & 12 & 1 & 2 & 3 & 4 & 5 & & 10 & \\
\hline 160 Coelioxys (Glyptocoelioxys) cerasiopleura Holmberg, 1903 & & 6 & & 1 & & 2 & 2 & & & & - & & 72,104 \\
\hline 161 Coelioxys (Glyptocoelioxys) sp.1 & & 1 & & & & & & & & & & 1 & \\
\hline 162 Megachile (Acentron) cfr. hastigera Moure, 1948 & & 2 & & & & 1 & & & 1 & & - & & 44,83 \\
\hline 163 Megachile (Acentron) lentifera Vachal, 1909 & 1 & 3 & & & & & 2 & 2 & & & - & & $28,40,50$ \\
\hline 164 Megachile (Austromegachile) fiebrigi Schrottky, 1908 & & 2 & & & & & & 2 & & & - & & 73 \\
\hline 165 Megachile (Austromegachile) sp.1 & 1 & & & & & & 1 & & & & - & & 50 \\
\hline 166 Megachile (Austromegachile) trigonaspis Schrottky, 1913 & & 1 & & & & & 1 & & & & - & & 50 \\
\hline 167 Megachile (Chrysosarus) sp.1 & & 1 & 1 & & & & & & & & - & & 48 \\
\hline 168 Megachile (Chrysosarus) sp.2 & 1 & & & & & & & & 1 & & - & & 44 \\
\hline 169 Megachile (Dactylomegachile) inquirenda Schrottky, 1913 & & 2 & & & & 1 & 1 & & & & - & & 77,104 \\
\hline 170 Megachile (Dactylomegachile) sp.1 & & 2 & 1 & 1 & & & & & & & - & & 55 \\
\hline 171 Megachile (Leptorachis) aureiventris Schrottky, 1902 & 1 & 5 & & 1 & & 3 & 2 & & & & - & & $32,44,74,75$ \\
\hline 172 Megachile (Leptorachis) friesei Schrottky, 1902 & 2 & 3 & & & & 4 & 1 & & & & - & & 74,112 \\
\hline 173 Megachile (Leptorachis) paulistana Schrottky, 1902 & & 2 & & 1 & & 1 & & & & & - & & 76 \\
\hline 174 Megachile (Leptorachis) apicipennis Schrottky, 1902 & & 1 & & 1 & & & & & & & & & \\
\hline 175 Megachile (Moureapis) anthidioides Radoszkowski, 1874 & & 13 & & & 1 & & 8 & 2 & 2 & & - & & $17,25,26,43,50,51$ \\
\hline 176 Megachile (Moureapis) sp.1 & 1 & 1 & & & & & & 1 & 1 & & - & & 39,44 \\
\hline 177 Megachile (Pseudocentron) curvipes Smith, 1853 & & 5 & & & 1 & 3 & 1 & & & & - & & $43,1,114$ \\
\hline 178 Megachile (Pseudocentron) sp.1 & & 1 & & & 1 & & & & & & - & & 37 \\
\hline 179 Megachile (Pseudocentron) cfr. terrestris Schrottky, 1902 & & 1 & 1 & & & & & & & & - & & \\
\hline 180 Megachile (Tylomegachile) orba Schrottky, 1913 & 1 & 1 & & 2 & & & & & & & - & & 66,75 \\
\hline 181 Megachile (?) iheringi Schrottky, 1913 & & 2 & & & & & & 2 & & & - & & 7,44 \\
\hline
\end{tabular}

Apêndice II. Lista das espécies de plantas visitadas por abelhas em uma área restrita de campo natural no Parque Estadual de Vila Velha, no período de outubro de 2002 a outubro de 2003. $\mathrm{N}$ = código da planta; $\mathrm{Nv}$ = número de visitas. Os códigos das espécies de abelhas estão de acordo com o Apêndice I.

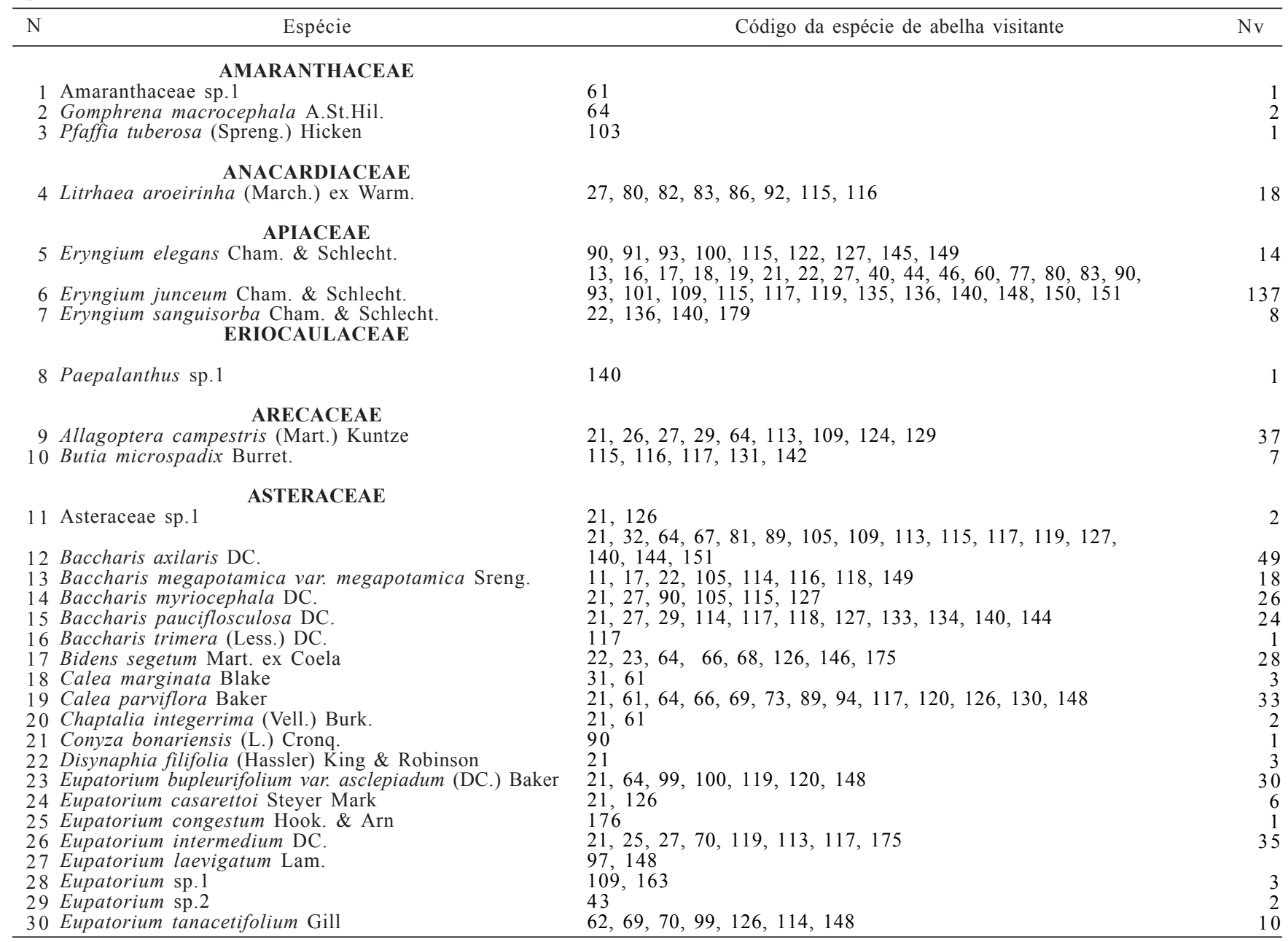


Apêndice II. Continuação.

\begin{tabular}{lll}
\hline $\mathrm{N}$ & Espécie & Código da espécie de abelha visitante \\
\hline
\end{tabular}

31 Haplopappus sp.1

32 Hieracium urvillei Sch. Bip.

33 Mikania micrantha H.B.K.

34 Mikania oblongifolia DC.

35 Orthopappus angustifolius (Sw.) Gleason

36 Perezia cubataensis Less

37 Senecio brasiliensis (Spreng.) Less.

38 Senecio oleosus Vell.

39 Solidago microglossa DC.

40 Stevia gardneriana Bak.

41 Symphyopappus compressus (Gardn) Robinson

42 Trichocline speciosa Less.

43 Trixis verbasciformis Less.

44 Verbesina sordescens DC.

45 Vernonanthura crassa (Vell.) H. Rob.

46 Vernonanthura rubicaulis (Less.) H. Robinson

47 Vernonia cognata var. sceptrum (Chodat) Cabrera

48 Vernonia crassa Ekman ex. Malme

49 Vernonia nudiflora Less.

50 Vernonia oligolepis Sch. Bip.

51 Vernonia platensis (Spreng.) Less.

52 Vernonia simplex Less.

53 Viguiera aspilioides Backer

54 Viguiera trichophylla Dusén
115

$73,141,171$

21

27,109

129,144

69

$21,119,121,147,178$

21

176

163

21

62,63

$21,27,59,61,63,64,73,79,97,98,101,110,114,117$,

$144,159,175,177$

$21,22,23,31,64,69,73,94,96,99,117,126,129,130$

$148,161,168,171,176,181$

$21,23,57,62,64,65,69,126,146$

22

$22,64,65,67,95,167$

$38,63,64,141,167$

$21,23,64,73$

$21,22,64,66,73,163,166,175,177$

$21,22,42,64,68,73,81,97,105,175$

$66,87,94$

$4,63,99,103,130$

$96,101,109$

CACTACEAE

55 Parodia ottonis var. vilavelhensis (Backberg e Voll) N.P. Taylor 1, 10, 48, 69, 112, 113, 129, 140, 168,170

CAESALPINIACEAE

56 Chamaecrista desvauxii var. triunviralis I. \& B.

57 Chamaecrista punctata (Vogel) I. \& B.

$1,9,22,23,29,104,111,119,128,129,140,145$

$22,101,108$

CAMPANULACEAE

58 Campanulaceae sp. 1

59 Wahlenbergia linarioides (Lam.) A. DC.

22,69

$4,21,52,61,69,71,129$

CARIOPHYLACEAE

60 Stellaria media (L.) Cirillo

$13,62,109$

CELASTRACEAE

61 Maytenus robusta Reiss

$63,90,127$

62 Clethra scabra Pers

\section{CLETHRACEAE}

\section{COMMELINACEAE}

63 Commelina elegans H.B.K.

64 Tradescantia cerinthoides Kunth.

21,114

22

129

\section{CONVOLVULACEAE}

65 Cuscuta cfr. racemosa Mart.

66 Ipomoea delphinioides Chaisy

67 Ipomoea sp.1

\section{CYPERACEAE}

68 Rhynchospora setigera (Kunth.) Bockl.

ERIOCAULACEAE

69 Eriocaulum dictyophyllum Korn.

EUPHORBIACEAE

70 Croton antisyphiliticus Mart.

71 Croton pallidulus var. pallidulus Baill.

72 Julocroton humilis Didricksen

27

$1,12,21,38,61,69,78,96,125,180$

$38,39,99$

105

21,117

160

\section{FABACEAE}

73 Centrosema virginianum (L.) Benth.

74 Crotalaria micans Link

75 Eriosema glabrum Mart. ex. Benth.

76 Galactia boavista (Vell.) Burk.

77 Stylosanthes gracilis H.B.K.

78 Zornia cryptantha Arech.

GERANIACEAE

79 Caesarea albiflora Cambess.

$2,22,23,24,31,34,35,73,76,97,120,129,148,164$

$21,27,29,31,32,34,75,110,171,172$

$47,50,73,180$

172

$8,11,21,47,113,168$

$7,9,43,141$

$7,12,21,47,69,129,137$

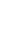


Apêndice II. Continuação.

\begin{tabular}{lc}
\hline $\mathrm{N}$ & Espécie \\
\hline & GESNERIACEAE \\
&
\end{tabular}

80 Sinningia canescens (Mart.) Wiehler

81 Iridaceae sp. 1

IRIDACEAE

82 Sisyrinchium iridifolium H.B.K.

83 Sisyrinchium restioides Spreng.

84 Sisyrinchium vaginatum Spreng.

\section{LAMIACEAE}

85 Peltodon rugosus Tolm.

LYTHRACEAE

86 Cuphea linarioides Cham. \& Schlecht.

\section{MALPHIGUIACEAE}

87 Aspicarpa pulchella (Griseb.) O'Don \& Lovat.

88 Byrsonima brachybotrya Nied.

89 Byrsonima psilandra Griseb.

\section{MALVACEAE}

90 Peltara edduardii (Hochr.) Kap \& Crist.

91 Sida acuta Burn

92 Sida macrodon DC.

MELASTOMATACEAE

93 Acisanthera alsinaefolia (DC.) Triana

94 Leandra sp.1

MIMOSACEAE

95 Mimosa daleoides Benth.

MYRTACEAE

96 Eugenia punicifolia (H.B.K.) DC.

97 Myrciaria delicatula (DC.) Berg

ORCHIDACEAE

98 Epidendron ellipticum Graham

OXALIDACEAE

99 Oxalis hispidula Zucc.

100 Oxalis sp.1

PASSIFLORACEAE

101 Passiflora lepidota Mart.

PORTULACACEAE

102 Portulaca sp.1

RUBIACEAE

103 Borreria poata (St. Hil.) DC

104 Borreria verticillata (L.) G. Mey.

105 Galianthe elegans Cabral

\section{SAPINDACEAE}

106 Serjania reticulata Cambess.

SCROPHULARIACEAE

107 Angelonia integerrima Spreng.

53

53

61,162

21

$21,61,73,102,113,117,129$

53

1

30

$52,55,56,57$

$33,51,57,108$

$38,40,51,58,61,63$

$21,22,23,95,159$

16

$28,97,110$

108

61

\section{$3,21,63$}

$61,84,86,118,132,109$

$21,22,23,58,64,94,129,139,140,141,142$

$21,103,105,109,114,117,129,133,139,140,160,169$

$117,125,139,140$

\section{SOLANACEAE}

108 Calibrachoa linoides (Sendltn.) Wijsman

109 Calibrachoa rupestris (Dusén) Wijsman 